\title{
Multi-objective Optimization of a Multi-chamber Perforated Muffler Using an Approximate Model and Genetic Algorithm
}

\author{
Shuguang Zuo, Kaijun Wei and Xudong Wu \\ Clean Energy Automotive Engineering Center, School of Automotive Studies, Tongji University, Shanghai 201804, \\ P.R. China
}

(Received 19 November 2013; accepted 11 December 2014)

Perforated mufflers are widely used in automotive intake and exhaust systems and need to be properly designed. However, multi-objective optimization in practical perforated muffler designs usually involves finite element or boundary element models, which demand a higher computation time for evolutionary algorithms. In this paper, an approximate model for transmission loss (TL) predictions is established by correcting the thickness correction coefficient in the transfer matrix using the data calculated by the finite element model (FEM). The approximate model is computationally cheap and applicable for TL predictions above the plane wave cut-off frequency. A popular evolutionary algorithm, NSGA-, amalgamated with the approximate model, has been adopted to carry out the multi-objective optimization of a multi-chamber perforated muffler. The goals of optimization are to maximize TL at the target frequency range, as well as to minimize the valleys of TL and the size of the muffler. Both transmission loss and insertion loss of the optimized muffler are measured. Numerical and experimental results are in good agreement and show significant improvements of acoustic performance precisely at the target frequency range. Consequently, the combination of the approximate model and the NSGA- algorithm provides a fast, effective, and robust approach to co-axial perforated muffler optimization problems.

\section{NOMENCLATURE}

a Radius of perforated holes (m)

$b \quad$ Distance between two perforated holes (m)

$c \quad$ Sound speed $\left(\mathrm{ms}^{-1}\right)$

$d \quad$ Inner tube diameter $(\mathrm{m})$

$D \quad$ Outer tube diameter (m)

$d_{h} \quad$ Diameter of perforated holes (m)

$f \quad$ Frequency $(\mathrm{Hz})$

$\omega \quad$ Angular frequency $(\omega=2 \pi f)$

$k \quad$ Wave number $(k=\omega / c)$

$j \quad$ Imaginary unit

$l \quad$ Total length of the chamber $(\mathrm{m})$

$l_{c} \quad$ Length of the perforated segment (m)

$l_{a} \quad$ Length of the non-perforated segment near inlet (m)

$l_{b} \quad$ Length of the non-perforated segment near outlet (m)

$p \quad$ Acoustic pressure $(\mathrm{Pa})$

$R_{e} \quad$ Expansion ratio $\left(R_{e}=D / d\right)$

$R_{l} \quad$ Perforated length ratio $\left(R_{l}=l_{c} / l\right)$

$t \quad$ Thickness of inner tube (m)

$t_{e} \quad$ Equivalent acoustic thickness (m)

$u \quad$ Acoustic particle velocity $\left(\mathrm{ms}^{-1}\right)$

$\rho \quad$ Air density $\left(\mathrm{kg} \cdot \mathrm{m}^{-1}\right)$

$\mu \quad$ Dynamic viscosity of air (Pa.s)

$\zeta_{p} \quad$ Specific acoustic impedance of the perforated tube

$A_{p} \quad$ Acoustic admittance of the perforated tube

$R_{h} \quad$ Specific resistance of acoustic impedance

$\alpha \quad$ thickness correction coefficient

$\eta \quad$ Porosity of the perforated tube

\section{INTRODUCTION}

Perforated mufflers have been widely used for reducing noise in automobiles, compressors, venting systems, etc. Various methods have been developed to predict the acoustic performance of perforated mufflers. The transfer matrix method based on the plane wave theory is the earliest and fastest method. Sullivan and Crocker ${ }^{1}$ first analysed the acoustic wave propagation in a co-axial perforated muffler and presented the coupled differential equations. Jayaraman and $\mathrm{Yam}^{2}$ then presented a decoupling solution for Sullivan and Crocker's ${ }^{1}$ equations and provided the transfer matrix of co-axial perforated mufflers. Further, Munjal ${ }^{3}$ improved the transfer matrix by considering the effects of mean flow, and developed a cascading method using the transfer matrices of basic acoustic elements for relatively simple mufflers. To analyse the complex mufflers with multiply-connected parts, Vijayasree and Mun$\mathrm{jal}^{4}$ developed an integrated transfer matrix method. However, these methods are only appropriate below the plane wave cutoff frequency. Numerical techniques such as finite element methods (FEM) and boundary element methods (BEM) have been proven to be more accurate at higher frequencies. Barbieri, et al..$^{5}$ applied the Galerkin-FEM to obtain the four-pole parameters to predict the acoustic performance. Kirby ${ }^{6}$ developed a fast and accurate hybrid finite element method for modelling automotive dissipative mufflers with perforated ducts and absorbing material. Wu, et $a l^{7}$ developed a direct mixedbody BEM to derive the four-pole parameters and predict the transmission loss of perforated mufflers. $\mathrm{Ji}$, et al. ${ }^{8}$ proposed a multi-domain BEM to analyse three-pass perforated duct mufflers. 


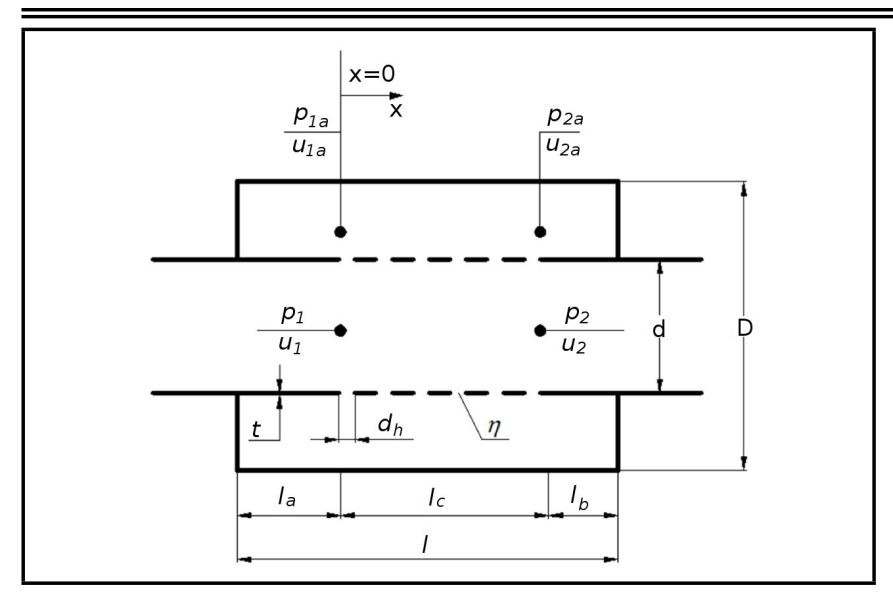

Figure 1. Schematic of a co-axial perforated muffler.

Practical muffler designs are usually governed by multiple conflicting criteria and constrains, which require multiobjective optimization. Evolutionary algorithms such as the genetic algorithm (GA) are suitable in this case owing to their robustness and the ability to avoid the drop in local optimum; however, the computation is time-consuming due to the large searching space. In previous papers, the shape optimizations of perforated mufflers with parallel-flow, cross-flow, and reverseflow ducts based on the transfer matrix method and various evolutionary algorithms were discussed. ${ }^{9-11}$ Airaksinen, et $a l .{ }^{12}$ provided a combined use of a hybrid finite method and genetic algorithm for the multi-objective optimization of various mufflers. However, these optimizations are either limited in use or computationally expensive. The idea behind the approximate model is to create an engineering method which uses an explicit model to evaluate design objectives and variables instead of a complex numerical model. Chang, et al. ${ }^{13,14}$ linked the objective functions with a polynomial neural network model (NNM) using the primary sample points obtained by the BEM, and the NNM was applied to HQ muffler optimizations. But the NNM was only valid in a certain frequency rather than a wide frequency range.

In the course of the authors' previous work, it was fortuitously found that by changing the thickness correction coefficient in the transfer matrix of the co-axial perforated mufflers, the accuracy of TL prediction was remarkably improved above the cut-off frequency, and the TL prediction under the cut-off frequency was as accurate as before. Hence, an appropriate model for TL predictions was established by introducing a formula of the thickness correction coefficient to the conventional transfer matrix. The formula of the thickness correction coefficient was obtained by the Taguchi design and polynomial regression, and the sample points were calculated by the FEM. Then, the approximate model was adopted to the multiobjective optimization of a multi-chamber perforated muffler, which is used for intake noise attenuation of a regenerative flow compressor in a fuel cell vehicle, combined with the GA. A prototype was produced based on the optimal results. Insertion loss measurements of the prototype were taken and the results have shown the optimization model to be convincing.

\section{APPROXIMATE MODEL}

As shown in Fig. 1, a co-axial perforated muffler is composed of an inner perforated tube and an outer resonating (a)

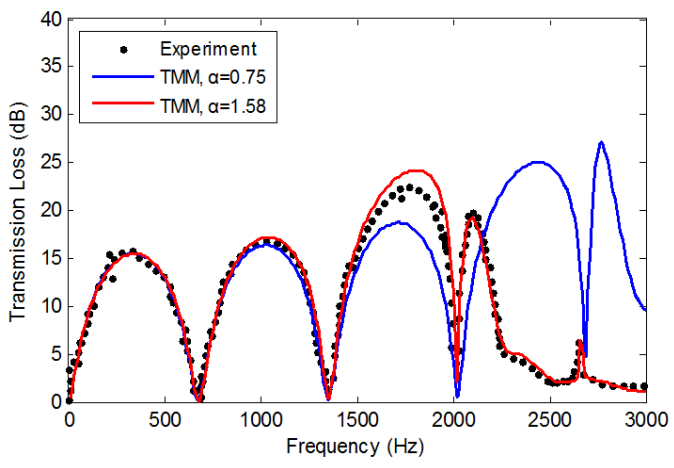

(b)

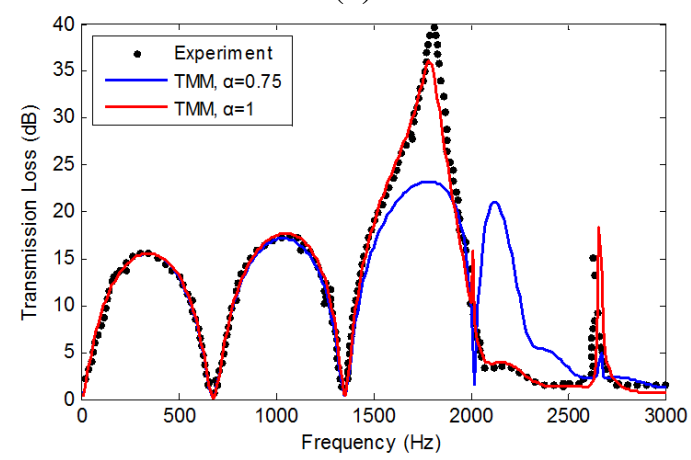

(c)

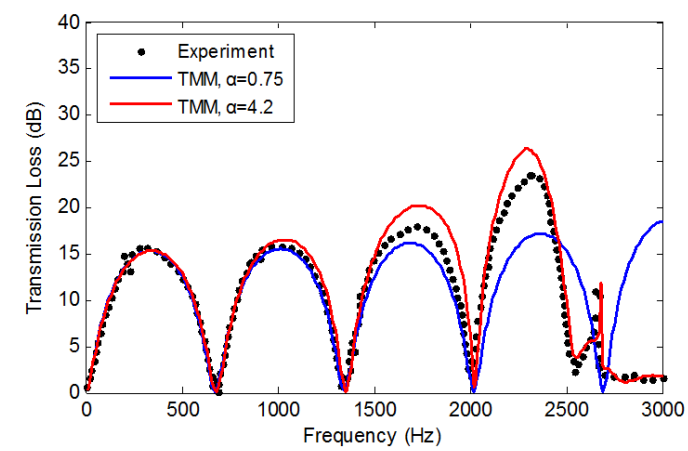

(d)

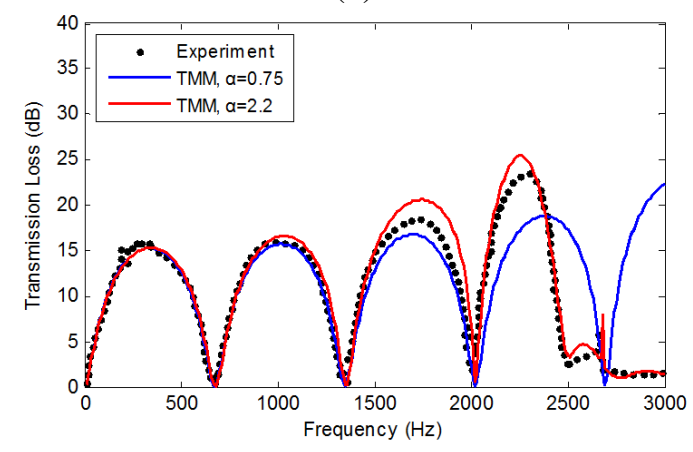

Figure 2. Transmission loss of perforated mufflers $[\mathrm{d}=49 \mathrm{~mm}, \mathrm{D}=164.4 \mathrm{~mm}$, $\mathrm{la}=\mathrm{lb}=0, \mathrm{lc}=257.2 \mathrm{~mm}, \mathrm{t}=0.9 \mathrm{~mm}$; (a) $\eta=8.4 \%, \mathrm{dh}=2.49 \mathrm{~mm}$; (b) $\eta=8.4 \%$, $\mathrm{dh}=4.98 \mathrm{~mm}$; (c) $\eta=25.7 \%, \mathrm{dh}=2.49 \mathrm{~mm}$; (d) $\eta=25.7 \%, \mathrm{dh}=4.98 \mathrm{~mm}] . \quad[\mathrm{Ex}-$ perimental data from Lee $(2005)^{16}$ ].

chamber. The transfer matrix [T] of co-axial perforated mufflers is derived in Appendix A. So the transmission loss (TL) can be calculated by ${ }^{3}$

$$
T L=20 \log \left(\frac{|\mathrm{A}+\mathrm{B}+\mathrm{C}+\mathrm{D}|}{2}\right) .
$$

It should be noted that the transfer matrix method (TMM) is 


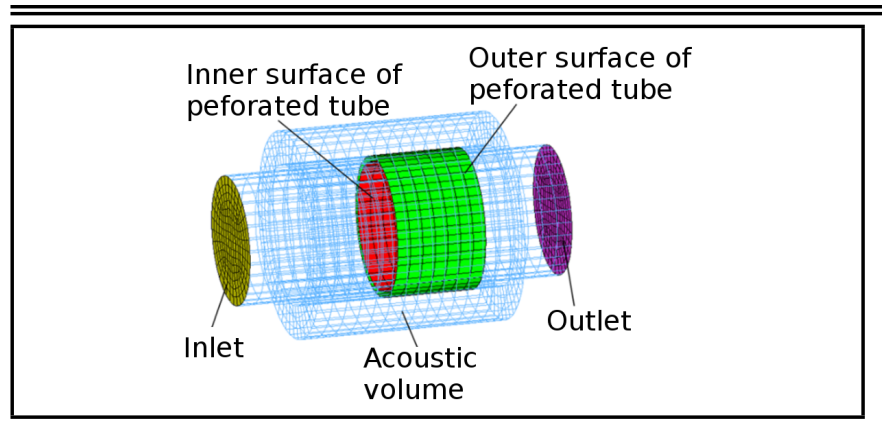

Figure 3. FE Model of the perforated muffler.

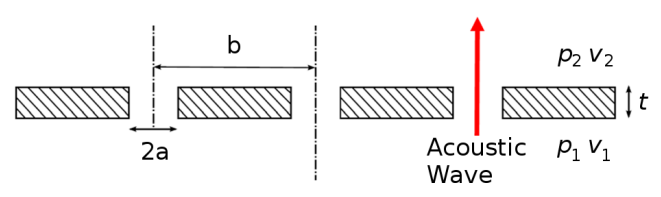

Figure 4. Cross section of a perforated plate.

valid only below the cutoff frequency of plane wave ${ }^{3}$

$$
f_{\text {cut }}=1.841 \frac{c}{\pi d_{0}}
$$

However, in the course of the authors' previous work on perforated mufflers, it was fortuitously found that by changing the thickness correction coefficient $\alpha$ in the expression of acoustic impedance to an appropriate value, the accuracy of TL prediction was remarkably improved above the cut-off frequency, and the TL prediction under the cut-off frequency was as accurate as before. Some cases are shown in Fig. 2. There are other cases showing a similar phenomenon. Corrected coefficient $\alpha$ takes into consideration mainly additional acoustical masses outside the holes coming from distributed radial velocities through a perforated wall. ${ }^{15}$ This suggests that a 1-D model suitable for TL prediction above the cut-off frequency may be obtained by introducing an appropriate model of the thickness correction coefficient to the conventional transfer matrix.

\subsection{Thickness Correction}

To acquire the thickness correction coefficient, the finite element method (FEM) was adopted to predict TL of perforated mufflers. The computations were taken by ACTRAN. The FE model is illustrated in Fig. 3. The Incident wave of the inlet is defined as unit sound intensity, and the reflect wave is defined as free. The outlet is defined as non-reflected.

Instead of meshing all the orifices, the transfer admittance boundary condition is defined between the inner and outer surfaces of a perforated tube. As shown in Fig. 4, the impedance of a single perforation can be written as

$$
Z_{p}=\frac{p_{1}-p_{2}}{\bar{v}}=R_{p}+j X_{p}
$$

where $p_{1}$ and $p_{2}$ are the upstream and downstream sound pressure, and $\bar{v}=v_{1}=v_{2}$ is the average particle velocity in the orifice.

Therefore, the impedance of the whole plate is

$$
\overline{Z_{p}}=\frac{Z_{p}}{\eta}=\frac{1}{\eta}\left(R_{p}+j X_{p}\right) ;
$$

where $\eta$ is the porosity of the perforated tube, and for a square grid, $\eta=\pi \frac{a^{2}}{b^{2}}$

In the above expressions, the impedance can be split into viscous effects contribution and end correction contribution. Using Crandall's theoretical model ${ }^{17}$ for viscous effects in narrow tubes, the impedance for a single perforation can be expressed as

$$
Z_{p}=j \omega \rho t\left[1-\frac{2}{\sqrt{-j} k_{s} a} \frac{J_{1}\left(\sqrt{-j} k_{s} a\right)}{J_{0}\left(\sqrt{-j} k_{s} a\right)}\right]^{-1} ;
$$

where $\omega$ is the angular frequency, $J_{0}$ and $J_{1}$ are order 0 and order 1 Bessel functions, and $k_{s} a=\sqrt{\frac{\omega \rho}{\mu}} a$ is the shear wavenumber.

For avoiding the evaluation of Bessel functions with complex argument, approximate solutions depending on the range of the dimensionless shear wavenumber $\mathrm{k} \mathrm{s}$ a can be deduced. When $\left|k_{s} a\right|>10$, the approximate solutions for Bessel functions can be written as

$$
\frac{J_{1}\left(\sqrt{-j} k_{s} a\right)}{J_{0}\left(\sqrt{-j} k_{s} a\right)}=-j .
$$

When Eq. (6) is applied to Eq. (5), the impedance contributed by viscous effects reduces to

$$
Z_{p}^{v i s c}=R_{p}^{v i s c}+j X_{p}^{v i s c}=\sqrt{2 \omega \mu \rho} \frac{t}{a}+j \omega \rho t .
$$

As for the end correction effects, the resistive end correction accounts for the frictional losses due to viscous effects at the surface of the plate, and the reactive end correction is due to the imaginary part of the radiation impedance at the tube's ends. The resistive and reactive end corrections are commonly adopted as $R_{p}^{c o r r}=\sqrt{8 \omega \mu \rho}$ and $X_{p}^{c o r r}=2 \omega \rho \frac{8}{3 \pi} a{ }^{18}$ However, the general expressions assume that there is no interaction between two adjacent holes. In the case for high porosity values, the interaction cannot be neglected. Therefore, a correction factor $\alpha_{p}=1.47 \sqrt{\eta}-0.47 \sqrt{\eta^{3}}$ is adopted to describe the interaction, ${ }^{19}$ and then the impedance of a single perforate is written as

$$
\begin{gathered}
R_{p}=R_{p}^{v i s c}+R_{p}^{c o r r}=\sqrt{8 \omega \mu \rho}\left(\frac{t}{2 a}+1\right) \\
X_{p}=X_{p}^{v i s c}+X_{p}^{c o r r}=\omega \rho\left[t+2 \frac{8}{3 \pi} a\left(1-\alpha_{p}\right)\right] .
\end{gathered}
$$

Taking Eqs. (8) and (9) into Eq. (4), the impedance of the perforated plane can be written as

$$
\begin{array}{r}
\overline{Z_{p}}=\frac{\sqrt{8 \omega \mu \rho}}{\eta}\left(\frac{t}{2 a}+1\right) \\
+j \frac{\omega \rho}{\eta}\left[t+2 \frac{8}{3 \pi} a\left(1-1.47 \sqrt{\eta}+0.47 \sqrt{\eta^{3}}\right)\right] .
\end{array}
$$

With applying Eq. (10) to the perforated tube wall, the influence of perforation on the sound field can be considered in the numerical computations. The incident sound power of the inlet $(W i)$ and outlet $(W o)$ can be acquired through computation, and thus the transmission loss can be expressed as

$$
T L=10 \log \frac{W_{i}}{W_{o}} .
$$

As shown in Fig. 5, the FEM results are in good agreement with experimental data; thus, the finite element method can 
Table 1. Parameters and levels used in the experiments.

\begin{tabular}{|c|c|c|c|c|c|c|c|}
\hline Symbol & Level 1 & Level 2 & Level 3 & Level 4 & Level 5 & Level 6 & Level 7 \\
\hline$d(\mathrm{~m})$ & 0.04 & 0.045 & 0.05 & 0.055 & 0.06 & 0.065 & 0.07 \\
\hline$R_{e}(D / d)$ & 1.6 & 1.7 & 1.8 & 1.9 & 2 & 2.1 & 2.2 \\
\hline$l(\mathrm{~m})$ & 0.06 & 0.07 & 0.08 & 0.09 & 0.1 & 0.11 & 0.12 \\
\hline$R_{l}\left(l_{c} / l\right)$ & 0.19 & 0.27 & 0.35 & 0.43 & 0.51 & 0.59 & 0.67 \\
\hline$t(\mathrm{~m})$ & 0.0008 & 0.0012 & 0.0016 & 0.002 & 0.0024 & 0.0028 & 0.0032 \\
\hline$d_{h}(\mathrm{~m})$ & 0.001 & 0.0015 & 0.002 & 0.0025 & 0.003 & 0.0035 & 0.004 \\
\hline$\eta$ & 0.14 & 0.18 & 0.22 & 0.26 & 0.3 & 0.34 & 0.38 \\
\hline
\end{tabular}

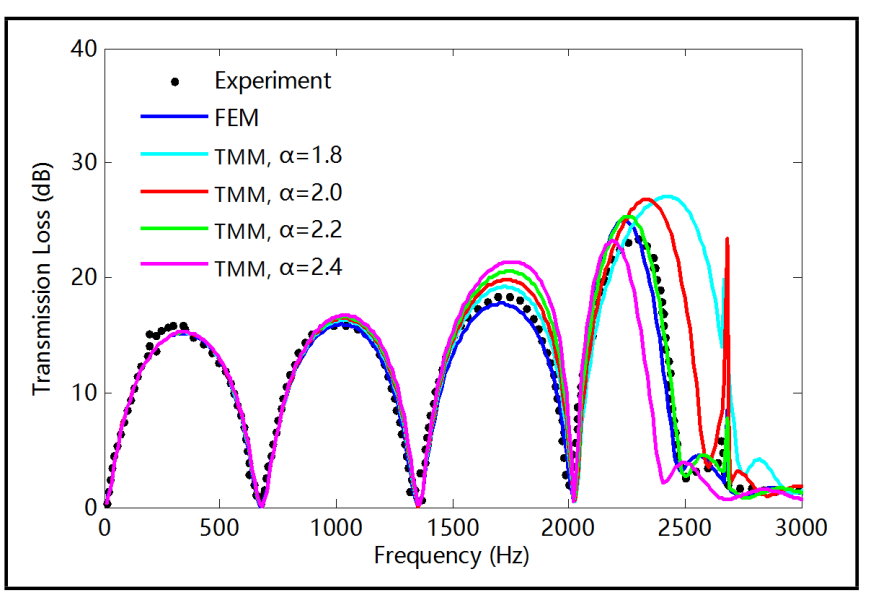

Figure 5. Transmission loss of perforated muffler; $[\mathrm{d}=49 \mathrm{~mm}, \mathrm{D}=164.4 \mathrm{~mm}$, $\mathrm{la}=\mathrm{lb}=0, \mathrm{lc}=257.2 \mathrm{~mm}, \mathrm{t}=0.9 \mathrm{~mm}, \eta=25.7 \%, \mathrm{dh}=4.98 \mathrm{~mm}$. [Experimental data from Lee $(2005)^{16}$ ].

be used as the numerical experiment. Altering the thickness correction coefficient $\alpha$ to make the transmission loss curve predicted by the TMM closer to that predicted by the FEM. An updated thickness correction coefficient $\hat{\alpha}$ was calculated to minimize the residual sum of squares of transmission loss:

$$
\min f(\hat{\alpha})=\sum_{i=1}^{n}\left(T L_{F E M}-T L_{T M M}(\hat{\alpha})\right)^{2}
$$

Therefore, the corrected acoustic thickness for TL prediction through the TMM above the cut-off frequency can be expressed as

$$
t_{e}=\frac{t+\hat{\alpha} d_{h}}{\eta}
$$

\subsection{Taguchi Design}

As illustrated in Fig. 1, there are eight design parameters of a straight perforated muffler. Because the switch of inlet and outlet won't change the transmission loss, the length of nonperforated segment $l_{a}$ and $l_{b}$ can be considered as one parameter. Obtaining a more accurate expression of the equivalent thickness and the design parameters means more experimental levels. The full factorial experimental design of seven parameters at seven levels would necessitate $7^{7}$ experiments. To save experimental time and cost, the Taguchi method ${ }^{20}$ was used for the design of experiments and a $L_{49}\left(7^{7}\right)$ orthogonal array was applied. The seven design parameters and their factor levels are summarized in Table 1. The experimental results are presented in Appendix B.

\subsection{Polynomial Repression}

Regression analysis is an approach to modelling the relationship between the dependent variable and explanatory variables. In this article, with the experimental data in Appendix B,
Table 2. ANOVA for regression model.

\begin{tabular}{||c|c|c|c|c|c|}
\hline Source & DF & SS & MS & $F$ & $p$ \\
\hline Model & 8 & 0.0019 & 0.0002 & 167.409 & 0.000 \\
\hline Residual & 40 & 0.000058 & 0.000 & & \\
\hline Total & 48 & 0.002 & & & \\
\hline$R^{2}=0.971$ & $R_{a d j}^{2}=0.965$ & & & & \\
\hline
\end{tabular}

a multiple linear stepwise regression analysis was performed to predict the equivalent thickness. Mathematical modelling was carried out by using a second-order polynomial equation as

$$
t_{e}=\beta_{0}+\sum_{i=1}^{k} \beta_{i} x_{i}+\sum_{i=1}^{k} \beta_{i i} x_{i}^{2}
$$

where $x_{i}=d, R_{e}, l, R_{l}, t, d_{h}, 1 / \eta i=1,2, \ldots, 7, \beta_{i}$ is the regression coefficient, and $k$ is the number of design parameters. The least square estimate method was adopted to interpret the estimated regression coefficient and the following equation was obtained:

$$
\begin{aligned}
& t_{e}=-0.0281+0.2064 d+0.0093 R_{e}+0.0542 l+0.0060 R_{l} \\
& +0.0018 R_{l}^{2}+2.8909 t+2.0056 d_{h}+1.4850 \times 10^{-4} \frac{1}{\eta^{2}} .
\end{aligned}
$$

The results of analysis of variance (ANOVA) are shown in Table 2. It calculates the sum of squares (SS), the mean of square (MS), the degree of freedom (DF), the ratio Fisher $(F)$, and significance $(p)$. In this model $F(8,48)=167.409>$ $2.907\left(F_{0.01}(8,48)\right)$, and overall significance $(p)$ is close to zero, which indicates a more than $99 \%$ confidence level of the statistical hypotheses. The determination coefficient $R^{2}$ and adjusted determination coefficient $R_{a d j}^{2}$ are equal to 0.971 and 0.965 , respectively, which indicate that $97.1 \%$ of the total variations are explained by the model.

The results of the regression coefficient test are shown in Table 3. The significances $(p)$ of all independent variables reach $\alpha$-level of 0.05 , which indicates that every independent variable has a strong effect on the equivalent thickness. The results predicted by the regression model are compared to experimental data in Fig. 6. It can be seen that model predictions present a good agreement with the experimental data, and the residual error rates are under $8 \%$. This means that the regression model provides a fair explanation of the relationship between the independent variables and the response.

\section{MODEL VALIDATION}

Before performing the optimization, the mathematical model should be validated first. Figure 7 shows the comparison between the predictions by the approximate model with experimental results from Lee. ${ }^{16}$ Figure 7 (a) shows that amplitude errors occurred in the theoretical prediction of muffler 1 at the third and fourth peak frequency, yet the errors are 


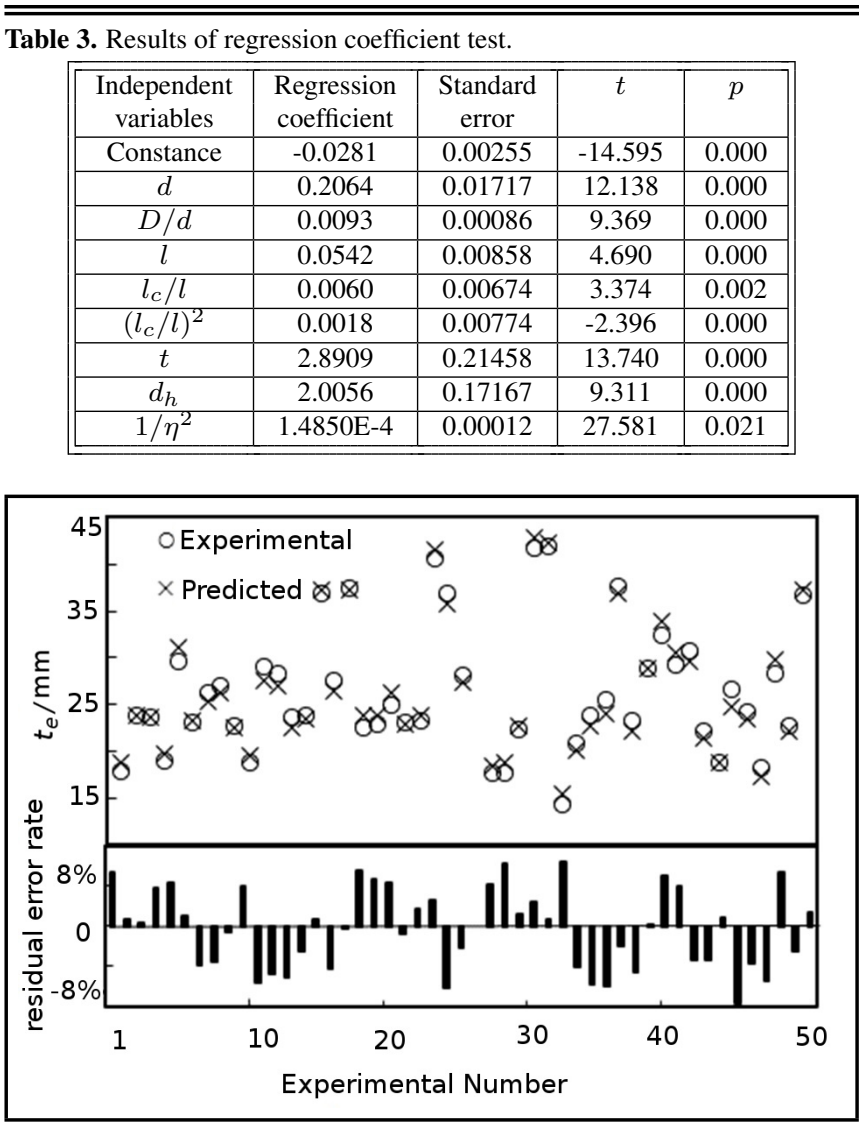

Figure 6. Comparison of regression model results with experimental data.

accepted in engineering applications. The theoretical predictions of other mufflers are in good agreement with experimental results. Consequently, the proposed mathematical model is proven to be valid above the plane wave cut-off frequency, and will be applied for the shape optimization of multi-chamber perforated mufflers.

\section{MULTI-OBJECTIVE OPTIMIZATION}

Most practical optimization problems are governed by multiple conflicting criteria and constraints. The general formulation of a multi-objective optimization problem can be described as follows:

$$
\begin{aligned}
& \min \left[f_{1}(x), f_{2}(x), \ldots, f_{n}(x)\right] \\
& \text { s.t. }\left\{\begin{array}{l}
g_{i}(x) \leq 0, i=1,2, \ldots, p \\
h_{j}(x)=0, j=1,2, \ldots, q
\end{array} ;\right. \\
& x \in S
\end{aligned}
$$

where $f=\left(f_{1}(\mathbf{x}), f_{2}(\mathbf{x}), \ldots, f_{n}(\mathbf{x})\right)$ represents the objective functions, $g_{i}(\mathbf{x}) \leq 0$ represents inequality constraints, and $h_{j}(\mathbf{x})=0$ represents equality constraints. $\mathbf{x}$ is the vector of $n$ independent variables that belongs to a feasible region $S$ of design space $\mathbf{R}^{n}$. Unlike the single objective optimization, the solution of a multi-objective optimization is not a single point, but a set of non-inferiority solutions known as Pareto optima.

In this section, a multi-objective optimization was presented for multi-chamber perforated mufflers of a regenerative flow compressor in a fuel cell vehicle. The approximate model presented in section 2 was applied to the transmission loss prediction of the muffler. The NSGA-II was adopted as the optimization algorithm. (a)

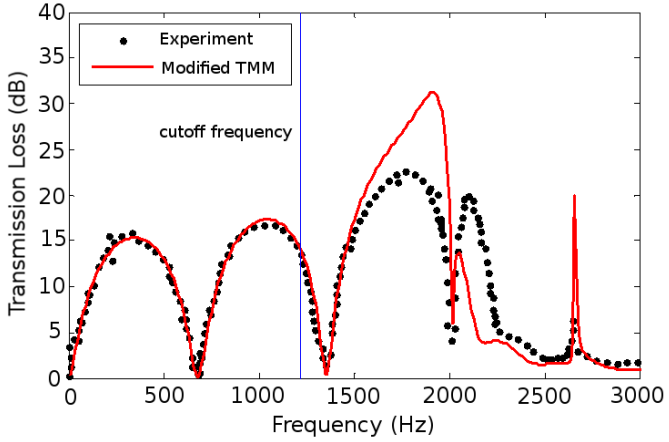

(b)

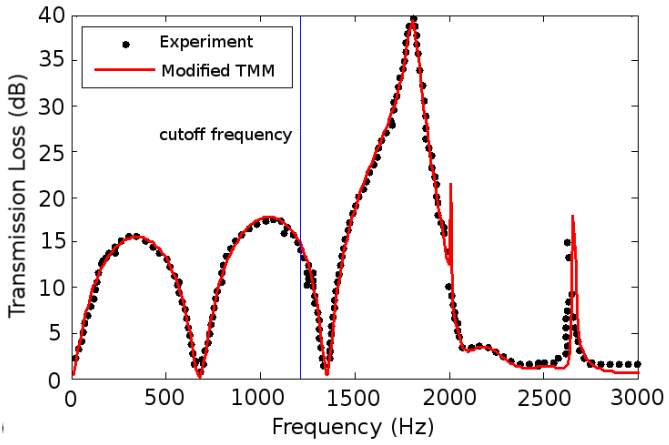

(c)

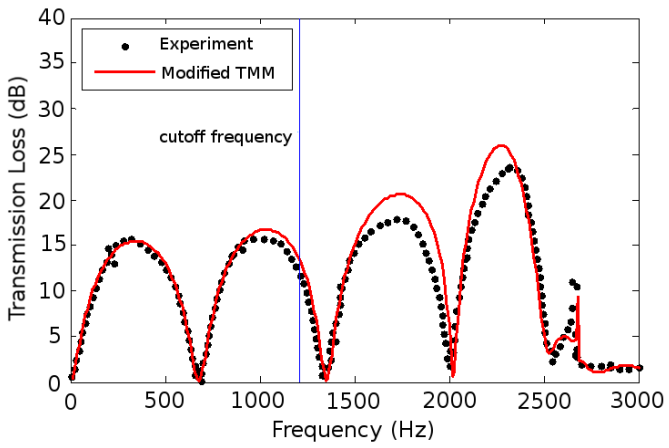

(d)

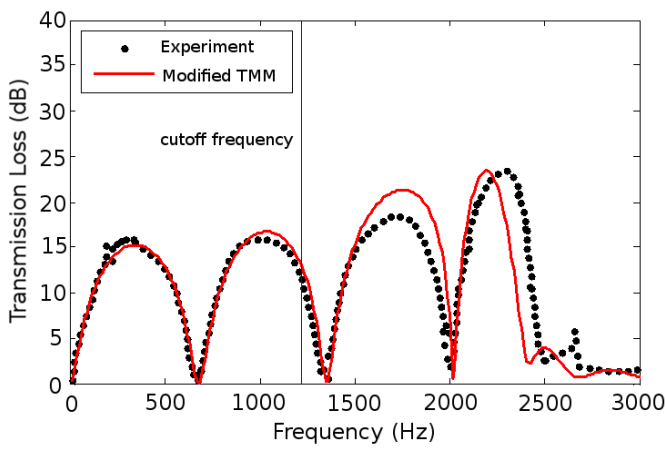

Figure 7. Comparison between predicted and experimental transmission loss $[\mathrm{d}=49 \mathrm{~mm}, \mathrm{D}=164.4 \mathrm{~mm}, \mathrm{la}=\mathrm{lb}=0, \mathrm{lc}=257.2 \mathrm{~mm}, \mathrm{t}=0.9 \mathrm{~mm}$; (a) $\eta=8.4 \%$, $\mathrm{dh}=2.49 \mathrm{~mm}$;(b) $\eta=8.4 \%, \mathrm{dh}=4.98 \mathrm{~mm}$; (c) $\eta=25.7 \%, \mathrm{dh}=2.49 \mathrm{~mm}$; (d) $\eta=25.7 \%, \mathrm{dh}=4.98 \mathrm{~mm}$ ]. [Experimental data from Lee $(2005)^{16}$ ].

\subsection{Objective Functions}

The objectives are to maximize the TL value at the target frequency range and minimize the volume of the muffler. In this case, the objective functions are as follows: 
1. The average value of TL at target frequency range:

$$
f_{1}(x)=-\frac{1}{\omega_{2}-\omega_{1}} \int_{\omega_{1}}^{\omega_{2}} T L(\omega) d \omega
$$

where $\omega_{1} \leq \omega \leq \omega_{2}$ is the frequency range. The blade number of the regenerative blower is 55 , and the common rotation speed is $1100-3800 \mathrm{rpm}$; hence, the blade passing frequency (BPF) is $1000-3500 \mathrm{~Hz}$. As the tonal noise at BPF is particularly annoying and contributes most to the noise level, ${ }^{21}$ the target frequency range was set at 1000-3500 Hz. The transmission loss can be calculated by Eq. (21).

2. Average valley value of TL: Though the average value of TL could be high, valleys may occur at certain frequency ranges. A threshold value was defined as $5 \mathrm{~dB}$ below the average value of TL; thus, the average valley value of TL can be expressed by Eq. (18) (on top of the next page), where $\omega_{i 1} \leq \omega \leq \omega_{i 2}$ is the ith frequency range of valleys, and $T L_{a v}$ is the average value of TL at 1000-3500 Hz.

3. Volume of the muffler:

$$
f_{3}(\mathrm{x})=\sum_{1}^{n} \frac{\pi D^{2} l_{i}}{4}, i=1,2,3
$$

where $l_{i}$ is the length of $i$ th resonating chamber.

\subsection{NSGA-II Algorithm}

Genetic algorithms (GAs) are adoptive heuristic search algorithms premised on the Darwinian notion of natural selection and evolution. The non-dominated sorting genetic algorithm (NSGA- II) developed by $\mathrm{Deb}^{22}$ is a multi-objective optimization algorithm using an elite-preserving strategy and an explicit diversity preserving mechanism. Like any conventional GAs, NSGA-II first creates a population of individuals that correspond to the design parameters randomly, and use selection, crossover, and mutation to create an offspring population. While conventional GAs select solutions based on the value of the fitness functions, NSGA-II makes selection based on non-domination rank and crowding distance. More details of can be found in Deb's paper. ${ }^{22}$ The structure of NSGA- II optimization is depicted in Fig. 8.

\subsection{Optimization Case}

A multi-chamber perforated muffler was adopted for inlet noise elimination of a regenerative flow compressor in a fuel cell vehicle. The schematic of the multi-chamber perforated muffler is given in Fig. 9. The multi-chamber perforated muffler includes three perforated tubes and the straight tubes which connect them. The four-pole constants of each element are considered unaffected. So, the overall transfer matrix of the muffler is given by the product of the individual element matrices:

$$
T^{*}=T_{S 1} \cdot T_{P 1} \cdot T_{S 2} \cdot T_{P 2} \cdot T_{S 3} \cdot T_{P 3} \cdot T_{S 4} ;
$$

where $T_{s}$ is the transfer matrix of the straight tube, and $T_{p}$ is the modified transfer matrix in the approximate model.

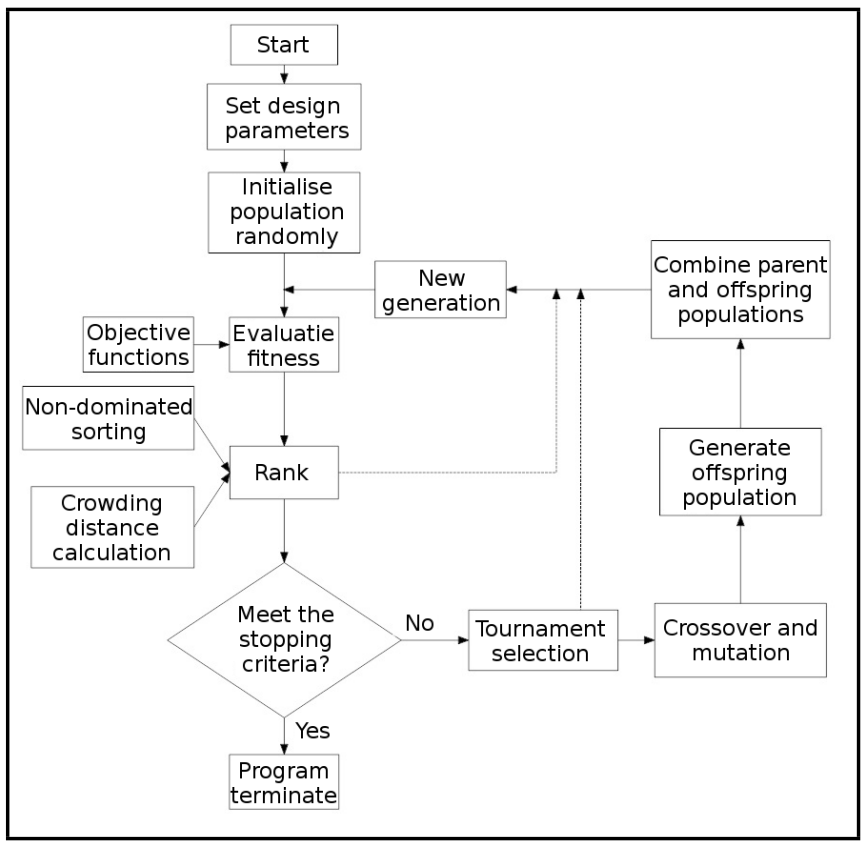

Figure 8. The block diagram of the NSGA-II algorithm.

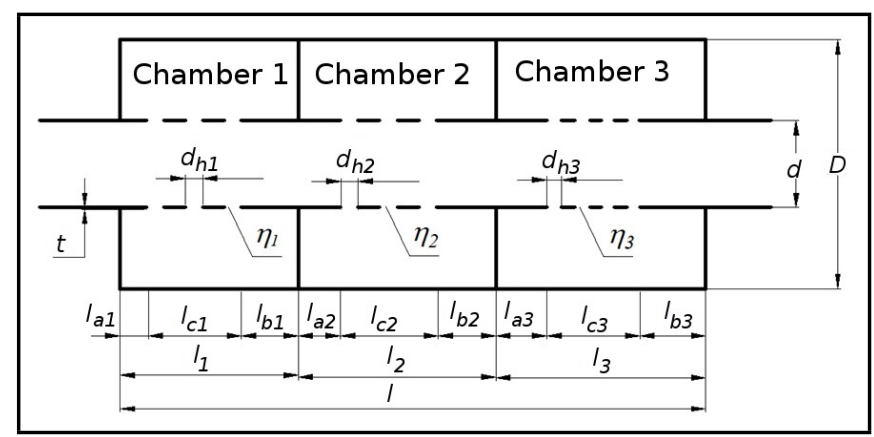

Figure 9. Schematic of the multi-chamber perforated muffler.

The four-pole constants of $T_{p}$ can be obtained by substituting Eqs. (13) and (15) into the conventional transfer matrix.

Transmission loss of the muffler can be calculated in terms of the four-pole constants as

$$
T L=20 \log \left(\frac{\left|T_{11}^{*}+T_{12}^{*}+T_{21}^{*}+T_{22}^{*}\right|}{2}\right) .
$$

The geometry of the muffler is determined by eighteen parameters, two of which are fixed, and sixteen are varied for optimization. The fixed parameters are the diameter of the resonating chamber $D=0.1 \mathrm{~m}$ and the diameter of the perforated tube $d=0.05 \mathrm{~m}$. Therefore, the cut-off frequency of the muffler is $f_{c u t}=1.841 \frac{c}{\pi D}=1990 \mathrm{~Hz}$. The ranges of optimization parameters of the $i$ th $(i=1,2,3)$ chamber are presented in Table 5 . The total length is constrained as $l=l_{1}+l_{2}+l_{3} \leq 0.2 \mathrm{~m}$.

The Pareto front of the three-chamber perforated muffler optimization is illustrated in Fig. 10. The Pareto solutions clearly reveal the conflicts among the three objects. Considering the priority of each object, four optimal design points are selected and presented in Table 4. The transmission losses of these four

Table 5. Ranges of optimization parameters of $i$ th chamber (i=1, 2, 3).

\begin{tabular}{|c|c|c|c|c|c|c|}
\hline Parameter & $l_{i}(\mathrm{~m})$ & $l_{a i} / l_{i}$ & $l_{b i} / l_{i}$ & $t(\mathrm{~m})$ & $d_{h i}(\mathrm{~m})$ & $\eta_{i}$ \\
\hline Lower limit & 0.05 & 0.12 & 0.12 & 0.001 & 0.001 & 0.1 \\
\hline Upper limit & 0.2 & 0.81 & 0.81 & 0.006 & 0.01 & 0.4 \\
\hline
\end{tabular}




$$
f_{2}(x)=\left\{\begin{array}{l}
\sum_{1}^{n} \frac{1}{\omega_{i 2}-\omega_{i 1}} \int_{\omega_{i 1}}^{\omega_{i 2}}\left[T L_{a v}-5-T L(\omega)\right] d \omega, T L_{a v}-5>T L(\omega), i=1,2, \ldots, n \\
0, T L_{a v}-5 \leq T L(\omega)
\end{array} ;\right.
$$

Table 4. Results of the three-chamber muffler optimization.

\begin{tabular}{|c|c|c|c|c|c|c|c|c|c|}
\hline No. & $\begin{array}{l}l_{1}(\mathrm{~m}) \\
l_{2}(\mathrm{~m}) \\
l_{3}(\mathrm{~m}) \\
\end{array}$ & $\begin{array}{l}l_{a 1} / l_{1} \\
l_{a 2} / l_{2} \\
l_{a 3} / l_{3} \\
\end{array}$ & $\begin{array}{l}l_{b 1} / l_{1} \\
l_{b 2} / l_{2} \\
l_{b 3} / l_{3} \\
\end{array}$ & $t(\mathrm{~m})$ & $\begin{array}{l}d_{h 1}(\mathrm{~m}) \\
d_{h 2}(\mathrm{~m}) \\
d_{h 3}(\mathrm{~m})\end{array}$ & $\begin{array}{l}\eta_{1} \\
\eta_{2} \\
\eta_{3} \\
\end{array}$ & $f_{1}(\mathbf{x})$ & $f_{2}(\mathbf{x})$ & $f_{3}(\mathbf{x})$ \\
\hline \multirow{3}{*}{1} & 0.0539 & 0.1945 & 0.1209 & \multirow{3}{*}{0.0020} & 0.0019 & 0.3367 & \multirow{3}{*}{-48.1} & \multirow{3}{*}{17.8} & \multirow{3}{*}{1.52} \\
\hline & 0.1230 & 0.3470 & 0.1191 & & 0.0017 & 0.2570 & & & \\
\hline & 0.0168 & 0.2231 & 0.1867 & & 0.0017 & 0.2941 & & & \\
\hline \multirow{3}{*}{2} & 0.0506 & 0.1939 & 0.1343 & \multirow{3}{*}{0.0028} & 0.0021 & 0.3146 & \multirow{3}{*}{-42.5} & \multirow{3}{*}{10.0} & \multirow{3}{*}{1.56} \\
\hline & 0.1307 & 0.3135 & 0.1642 & & 0.0015 & 0.2326 & & & \\
\hline & 0.0168 & 0.2231 & 0.1867 & & 0.0017 & 0.2941 & & & \\
\hline \multirow{3}{*}{3} & 0.0352 & 0.1974 & 0.1493 & \multirow{3}{*}{0.0021} & 0.0018 & 0.3246 & \multirow{3}{*}{-41.4} & \multirow{3}{*}{19.4} & \multirow{3}{*}{1.33} \\
\hline & 0.1164 & 0.3589 & 0.1144 & & 0.0020 & 0.3358 & & & \\
\hline & 0.0175 & 0.2097 & 0.0978 & & 0.0018 & 0.3529 & & & \\
\hline \multirow{3}{*}{4} & 0.0328 & 0.1713 & 0.1608 & \multirow{3}{*}{0.0021} & 0.0017 & 0.3027 & \multirow{3}{*}{-34.9} & \multirow{3}{*}{16.9} & \multirow{3}{*}{1.13} \\
\hline & 0.0975 & 0.3184 & 0.1230 & & 0.0019 & 0.2433 & & & \\
\hline & 0.0137 & 0.2409 & 0.1127 & & 0.0017 & 0.2773 & & & \\
\hline
\end{tabular}

(a)

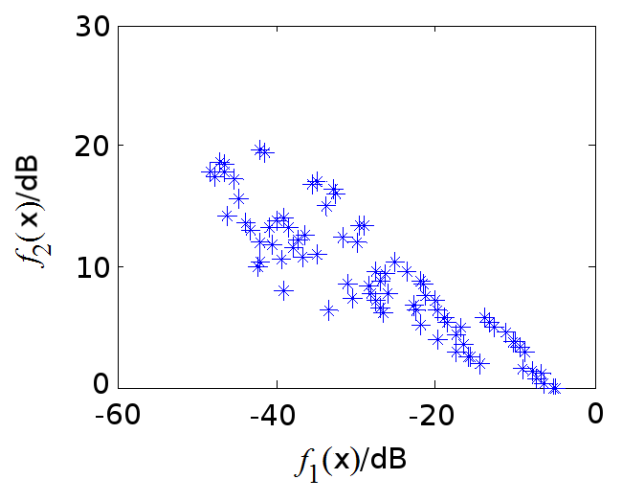

(b)

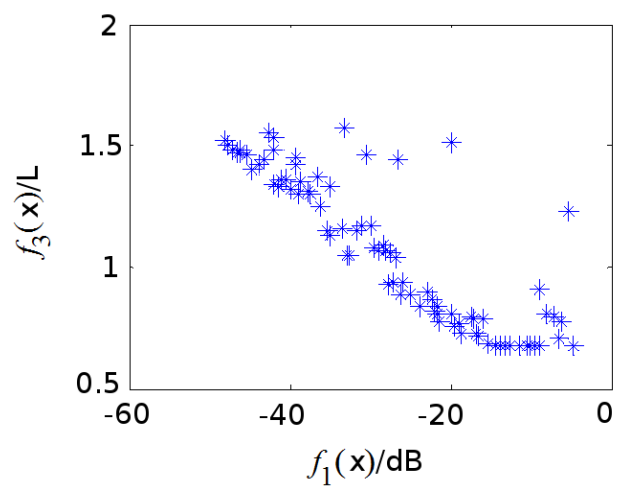

Figure 10. Pareto front of the multi-chamber muffler optimization.

mufflers are shown in Fig. 11. For each of the four mufflers, the transmission loss at the target frequency range is much larger than other frequency ranges. Muffler No. 1 is considered the best because its average TL value is the highest, and the lowest TL value is over $20 \mathrm{~dB}$, also with an acceptable size.

\section{EXPERIMENTAL VALIDATION}

Transmission loss and insertion loss measurements were carried out in order to validate the optimization results. The parameters of the muffler are shown as No. 1 in Table 4. The measurements were taken in a reverberation room.

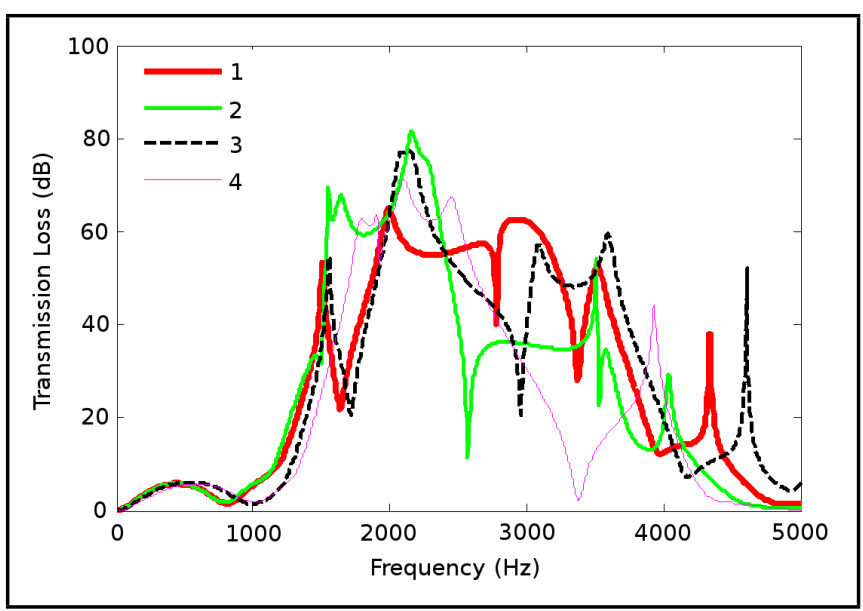

Figure 11. Transmission losses of optimized mufflers.

\subsection{Transmission Loss Measurement}

The two-load method was applied to measure the transmission loss of the muffler. The schematic diagram and the photograph of the measurement are shown in Fig. 12. The experimental apparatus consisted of three parts: the source, the test section, and the data processing system. The loudspeaker driven by a power amplifier generated white noise signals containing all frequencies of interest. In the test section, the tested muffler was installed in an impedance tube. Four microphones were installed both upstream and downstream of the muffler. The LMS data acquisition system was used to collect the signals from the microphones and then feed the data to the computer-controlled Fourier analyser.

In this measurement, two loads were achieved by an outlet tube with and without an end cap. The transmission loss can be obtained by using four-pole equations. ${ }^{23}$

The sound pressure measured at location $1 \sim 4$ can be expressed as

$$
\begin{gathered}
p_{1}=p_{u}^{+} e^{j k\left(L_{1}+L_{2}\right)}+p_{u}^{-} e^{-j k\left(L_{1}+L_{2}\right)} \\
p_{2}=p_{u}^{+} e^{j k L_{2}}+p_{u}^{-} e^{-j k L_{2}} \\
p_{3}=p_{d}^{+} e^{-j k L_{3}}+p_{d}^{-} e^{j k L_{3}} \\
p_{4}=p_{d}^{+} e^{-j k\left(L_{3}+L_{4}\right)}+p_{d}^{-} e^{j k\left(L_{3}+L_{4}\right)}
\end{gathered}
$$




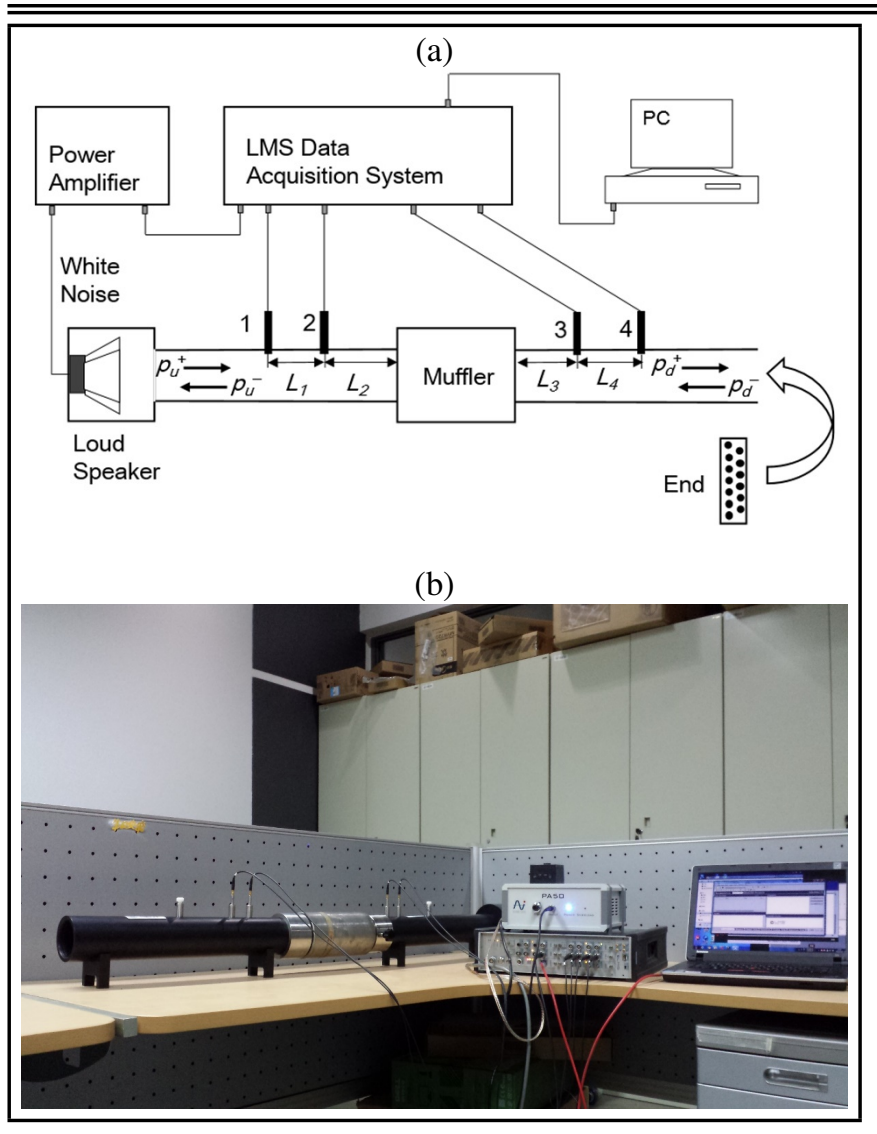

Figure 12. Experimental setup; (a) diagram of test arrangement; (b) photograph of test environment.

where the superscript + refers to incident waves, and the superscript - refers to reflected waves; the subscript $u$ refers to the region upstream of the muffler, and $d$ refers to the region downstream of the muffler.

Using the wave decomposition theory, the incident and reflected wave can be calculated by equations

$$
\begin{gathered}
p_{u}^{+}=\frac{p_{1} e^{-j k L_{2}}-p_{2} e^{-j k\left(L_{1}+L_{2}\right)}}{e^{j k L_{1}}-e^{-j k L_{1}}} ; \\
p_{u}^{-}=\frac{p_{1} e^{j k L_{2}}-p_{2} e^{j k\left(L_{1}+L_{2}\right)}}{e^{-j k L_{1}}-e^{j k L_{1}}} \\
p_{d}^{+}=\frac{p_{3} e^{j k\left(L_{3}+L_{4}\right)}-p_{4} e^{j k L_{3}}}{e^{j k L_{4}}-e^{-j k L_{4}}} \\
p_{d}^{-}=\frac{p_{3} e^{-j k\left(L_{3}+L_{4}\right)}-p_{4} e^{-j k L_{3}}}{e^{-j k L_{4}}-e^{j k L_{4}}}
\end{gathered}
$$

The four-pole equation for incident and reflected waves upstream and downstream of the muffler can be expressed as

$$
\begin{aligned}
& \left\{\begin{array}{l}
p_{u a}^{+} \\
p_{u a}^{-}
\end{array}\right\}=\left[\begin{array}{cc}
A & B \\
C & D
\end{array}\right]\left\{\begin{array}{l}
p_{d a}^{+} \\
p_{d a}^{-}
\end{array}\right\} ; \\
& \left\{\begin{array}{c}
p_{u b}^{+} \\
p_{u b}^{-}
\end{array}\right\}=\left[\begin{array}{ll}
A & B \\
C & D
\end{array}\right]\left\{\begin{array}{l}
p_{d b}^{+} \\
p_{d b}^{-}
\end{array}\right\} ;
\end{aligned}
$$

where the subscript $a$ refers to configuration without the end cap, and $b$ refers to configuration with the end cap.

Therefore, the transmission loss of the muffler can be calculated as

$$
T L=20 \log _{10}|A|=20 \log _{10}\left|\frac{p_{u a}^{+} p_{d b}^{-}-p_{u b}^{+} p_{d a}^{-}}{p_{d a}^{+} p_{d b}^{-}-p_{d b}^{+} p_{d a}^{-}}\right| .
$$

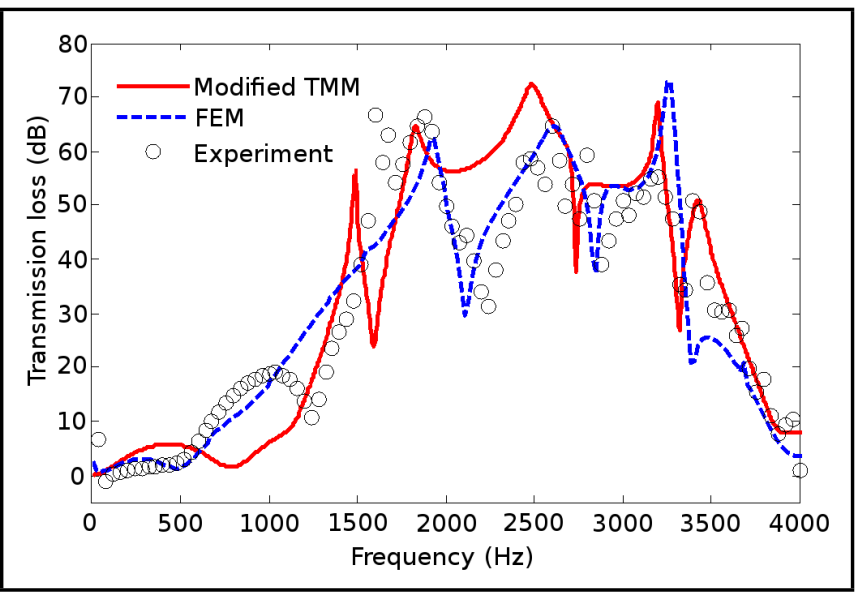

Figure 13. Transmission loss comparison.

Figure 13 shows the comparison of the experimental, theoretical, and numerical predictions of transmission loss. The transmission loss predicted by the approximate model is consistent with the FEM results on the whole, while the peak at $1530 \mathrm{~Hz}$ doesn't appear in the FEM results, and the amplitudes of theoretical results are higher than the FEM at certain frequency.

It should be noticed that the thickness correction is based on the FEM results of single-chamber perforated mufflers. So, the application of the modified TMM to the transmission loss predictions of multi-chamber perforated mufflers may lead to a larger deviation. In order to test this hypothesis, transmission loss of each chamber was calculated by a modified TMM and FEM, and the results were given in Fig. 14. As shown in Fig. 14, the transmission losses predicted by modified TMM of chamber 1 and chamber 3 are in good agreement with the FEM results. As for chamber 2, the transmission loss curves are quite close on the whole. The errors are mainly the second peak at $2750 \mathrm{~Hz}$, which is $2900 \mathrm{~Hz}$ in the FEM results, and the third peak at $3460 \mathrm{~Hz}$, which is $3330 \mathrm{~Hz}$ in the FEM results. Nonetheless, errors are acceptable considering the target frequency bandwidth is quite broad.

Note, however, that the most remarkable error of TL predictions of the optimized muffler at $1530 \mathrm{~Hz}$, which comes from chamber 2 as shown in Fig. 14 (b), agrees quite well with the FEM results of the single chamber 2 calculation. Therefore, the reason for the calculation error at $1530 \mathrm{~Hz}$ of the optimized muffler is not the error of chamber 2, but the coupling effect of the three chambers. Figure 15 shows the pressure maps of both the optimized muffler and chamber 2 at $1530 \mathrm{~Hz}$. In the case of chamber 2, it shows a first order radial duct modal at $1530 \mathrm{~Hz}$, which causes the corresponding peak of transmission loss. Yet this modal of chamber 2 in the optimized muffler disappears due to the effect of chamber 1 .

\subsection{Insertion Loss Measurement}

Though transmission loss is most easily predicted theoretically, insertion loss is more widely used in engineering applications. Besides, the transmission losses are predicted without mean flow, while the muffler in the compressor system operates with grazing flow, and the grazing flow at high speeds may reduce the transmission loss. ${ }^{24}$ Thus, it is necessary to measure the insertion loss of the muffler under the typical operating conditions of the compressor. 


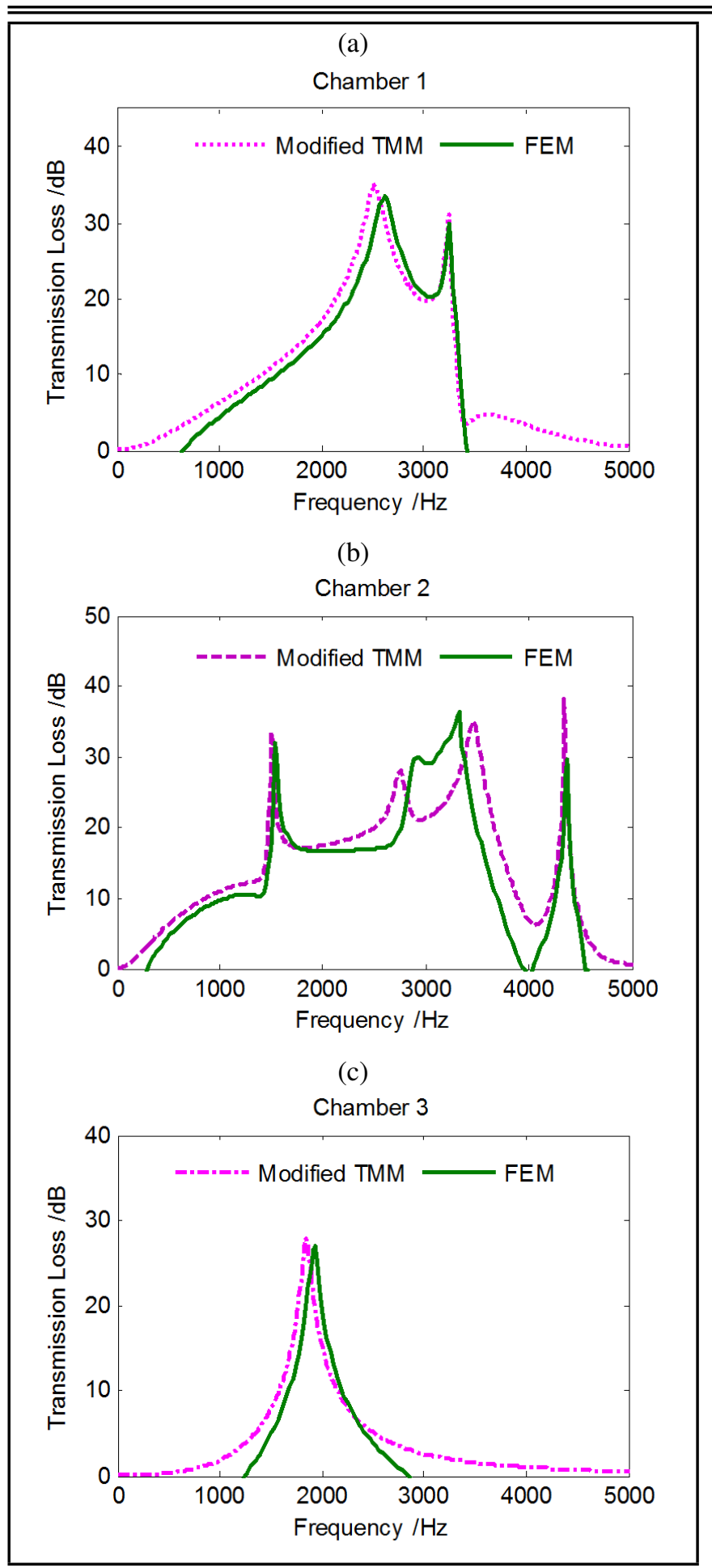

Figure 14. Transmission loss comparisons of each chamber: (a) Chamber 1; (b) Chamber 2; (c) Chamber 3.

The diagram and the photograph of the insertion loss measurement are shown in Fig. 16. The compressor and the motor were covered with absorbing material. A microphone was installed $0.5 \mathrm{~m}$ away from the compressor inlet and $45^{\circ}$ to the axial direction. Sound pressure levels (SPL) were measured by the microphone with and without the muffler. Measurements were taken at every $400 \mathrm{rpm}$ for 1000-3800 rpm range in steady conditions, and from $1000 \mathrm{rpm}$ to $3800 \mathrm{rpm}$ in run-up conditions.

Figure 17 shows the SPL of intake noise in run-up conditions. Notice that the SPL of inlet noise was remarkably atten-

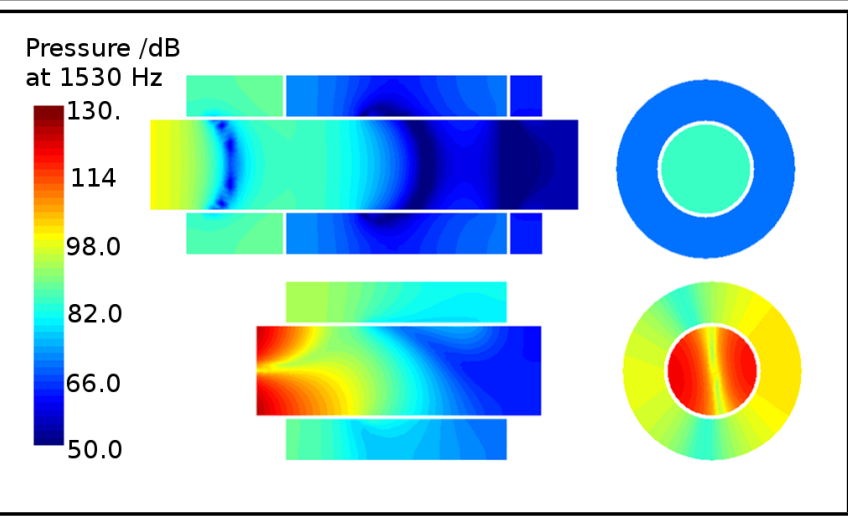

Figure 15. Pressure maps of the optimized muffler and chamber 2.

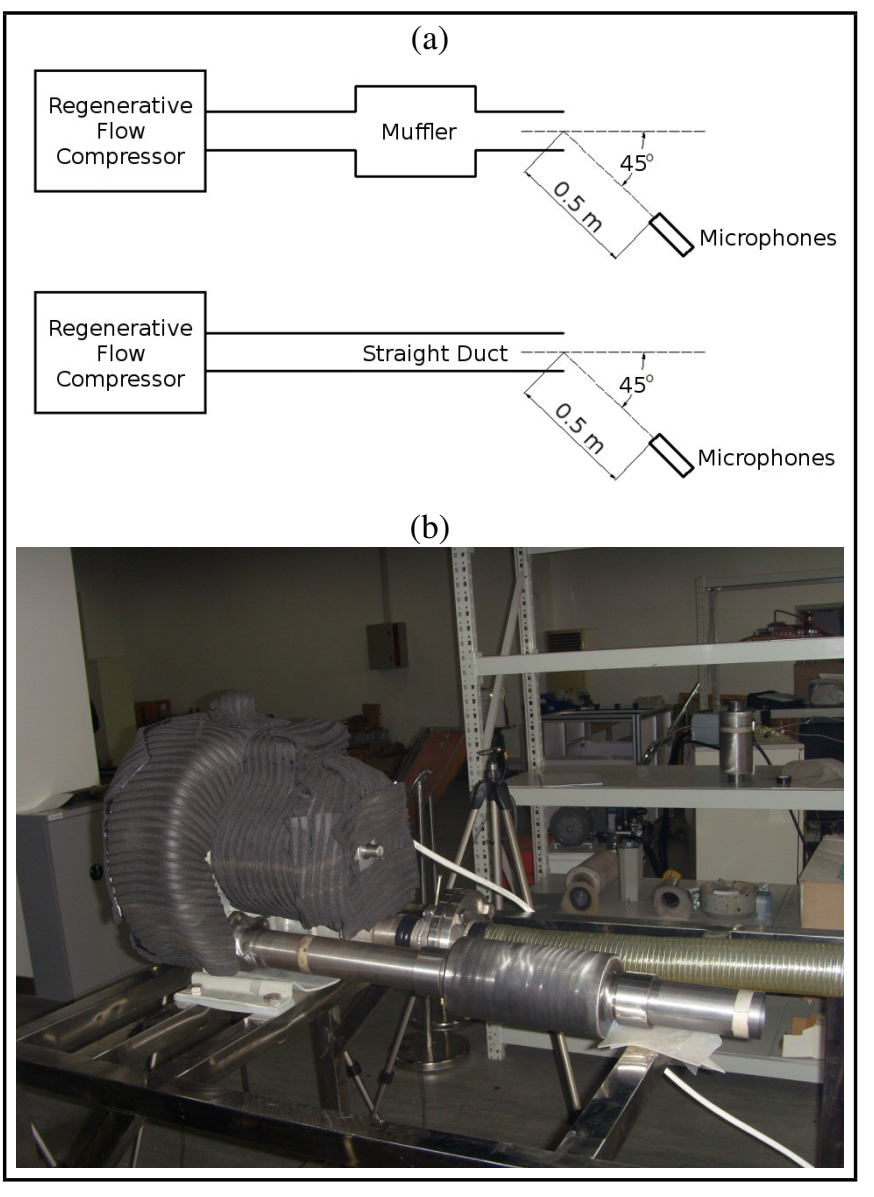

Figure 16. Experimental setup: (a) diagram of test arrangement; (b) photograph of test environment.

uated at the target frequency range of 1000-3500 Hz with mufflers. Figure 18 shows the SPL of intake noise at 3000 RPM. The SPL was reduced by $25 \mathrm{~dB}$ at $1000-3500 \mathrm{~Hz}$. And the tonal noise level at BPF was reduced from $92.35 \mathrm{~dB}$ to $57.94 \mathrm{~dB}$ in a drop of $34.41 \mathrm{~dB}$. In other stationary conditions, tonal noise levels also appeared the highest of the full frequency band, as well as the insertion loss at BPF.

\section{CONCLUSION}

An approximate model was established by introducing the formula of the thickness correction coefficient in the conventional transfer matrix. The thickness correction was calculated precisely by comparing the transmission loss curves predicted by the TMM with those predicted by the FEM, and the cor- 


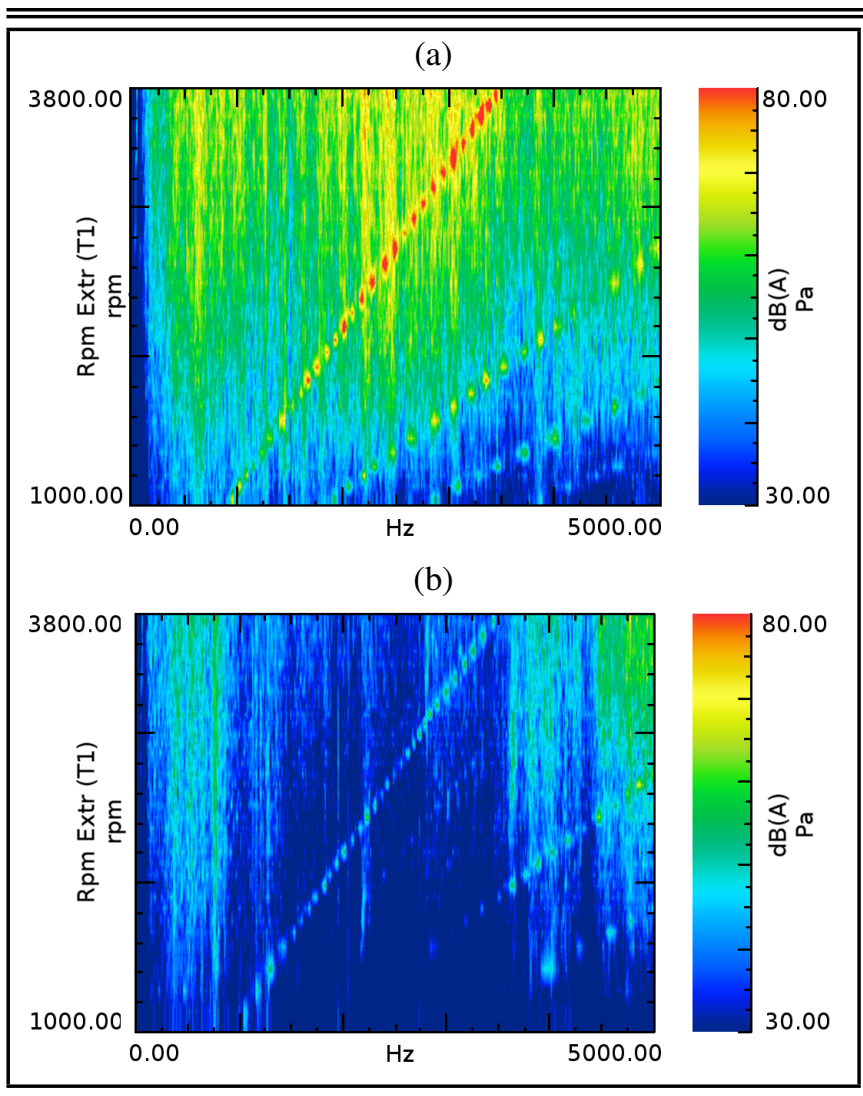

Figure 17. SPL of intake noise under run-up conditions: (a) without muffler; (b) with muffler.

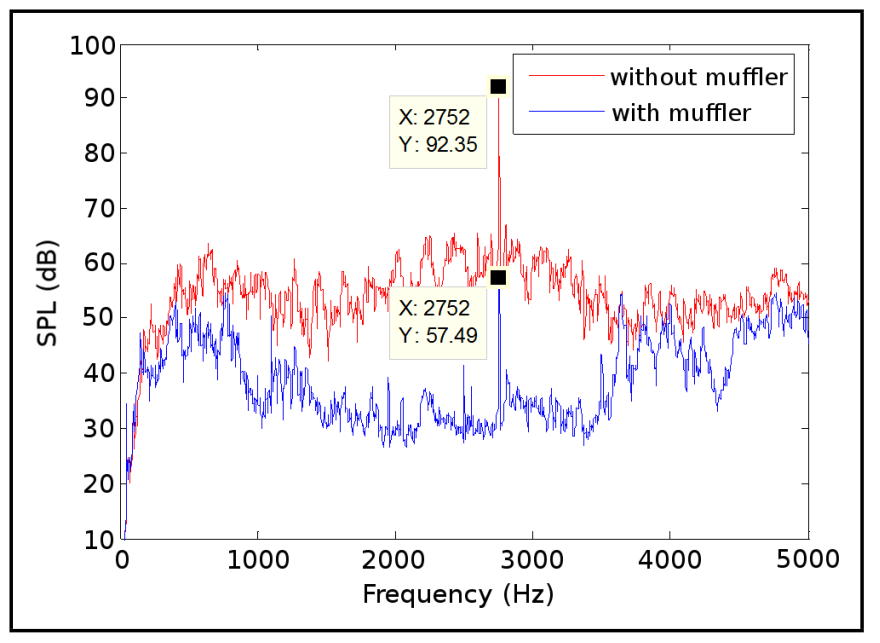

Figure 18. SPL of intake noise at 3000 RPM.

rection formula was obtained by the Taguchi design and polynomial regression analysis. The approximate model has been proven effective within acceptable accuracy limits.

In this study, multi-objective shape optimization of multichamber perforated mufflers was presented. NSGA- II was used as the optimization algorithm, and transmission loss was calculated by the approximate model. Certain Pareto solutions were chosen, and a prototype was manufactured based on one of the Pareto solutions. Both transmission loss and insertion loss of the optimized muffler were measured. Numerical and experimental results are in good agreement and show significant improvements of acoustic performance precisely at the target frequency range.

Consequently, the combination of the approximate model and the NSGA-II algorithm provides a fast, effective, and robust approach to co-axial perforated muffler optimization problems.

\section{ACKNOWLEDGEMENTS}

Authors are grateful for the financial support by National Natural Science Foundation of China (No. 51305303) and National Major Scientific Instrument Equipment Project of China (2012YQ150256).

\section{APPENDIX A. TRANSFER MATRIX OF PERFORATED MUFFLER}

As shown in Fig. 1, a co-axial perforated muffler is composed of an inner perforated tube and an outer resonating chamber. Under the isentropic progresses, for a perforated muffler without mean flow, the governing equations can be written $a^{3}$ in Eq. (1), (on top of the next page). where $\alpha_{1}=k^{2}-\frac{4 j k}{d \zeta_{p}}, \alpha_{2}=\frac{4 j k}{d \zeta_{p}}, \alpha_{3}=\frac{4 j k d}{\left(D^{2}-d^{2}\right) \zeta_{p}}, \alpha_{4}=k^{2}-\alpha_{3}$, $k=\frac{2 \pi f}{c}$, and $\zeta_{p}=\frac{p_{1}-p_{1 a}}{\rho c u_{h}}$ is the normalized specific acoustic impedance of the perforated tube, which is defined as

$$
\zeta_{p}=\frac{R_{h}+j k\left(t+\alpha d_{h}\right)}{\eta}
$$

where $R_{h}$ is the specific resistance, and $\alpha$ is the thickness correction coefficient.

Eq. (1) can be conveniently expressed in following matrix form Eq. (3) (see the top of the next page).

Decoupling Eq. 3, the relationship of acoustic pressure and normal particle velocity can be obtained as

$$
\left[\begin{array}{c}
p_{1} \\
\rho c u_{1} \\
p_{1 a} \\
\rho c u_{1 a}
\end{array}\right]=[\Omega]\left[\begin{array}{c}
C_{1} \mathrm{e}^{\lambda_{1} x} \\
C_{2} \mathrm{e}^{\lambda_{2} x} \\
C_{3} \mathrm{e}^{\lambda_{3} x} \\
C_{4} \mathrm{e}^{\lambda_{4} x}
\end{array}\right] ;
$$

where $\lambda$ is the eigenvalues of $[N]$, and $[\Omega]$ is the model matrix formed by eigenvectors of $[N]$ :

$$
\begin{gathered}
\lambda= \pm \sqrt{-\left(\alpha_{1}+\alpha_{4}\right) / 2 \pm \sqrt{\left(\alpha_{1}-\alpha_{4}\right)^{2} / 4+\alpha_{2} \alpha_{3}}} ; \\
\left\{\begin{array}{c}
\Omega_{1 i} \\
\Omega_{2 i} \\
\Omega_{3 i} \\
\Omega_{4 i}
\end{array}\right\}=\left\{\begin{array}{c}
1 \\
j \lambda_{i} / k \\
-\left(\alpha_{1}+\lambda_{i}^{2}\right) / \alpha_{2} \\
-j \lambda_{i}\left(\alpha_{1}+\lambda_{i}^{2}\right) /\left(k \alpha_{2}\right)
\end{array}\right\} i=1234 .
\end{gathered}
$$

Thus, the relationship of acoustic pressure and particle velocity between $x=0$ and $x=l_{c}$ can be obtained as

$$
\left[\begin{array}{c}
p_{1}(0) \\
\rho c u_{1}(0) \\
p_{1 a}(0) \\
\rho c u_{1 a}(0)
\end{array}\right]=[\mathrm{R}]\left[\begin{array}{c}
p_{1}\left(l_{c}\right) \\
\rho c u_{1}\left(l_{c}\right) \\
p_{1 a}\left(l_{c}\right) \\
\rho c u_{1 a}\left(l_{c}\right)
\end{array}\right]
$$

where $[R]=[\Omega][E][\Omega]^{-1},[\mathrm{E}]=\operatorname{diag}\left(\exp \left(-\lambda_{i} l_{c}\right)\right), i=$ $1,2,3,4$

The boundary conditions of outer tube are given as

$$
\left\{\begin{array}{l}
\rho_{0} c_{0} u_{1 a}=-j \tan \left(k l_{a}\right) p_{1 a} \\
\rho_{0} c_{0} u_{2 a}=j \tan \left(k l_{b}\right) p_{2 a}
\end{array}\right.
$$




$$
\frac{\mathrm{d}^{2} p_{1}}{\mathrm{~d} x^{2}}+\alpha_{1} p_{1}+\alpha_{2} p_{1 a}=0 \frac{\mathrm{d}^{2} p_{1 a}}{\mathrm{~d} x^{2}}+\alpha_{3} p_{1}+\alpha_{4} p_{1 a}=0 j k \rho c u_{1}=\frac{\mathrm{d} p_{1}}{\mathrm{~d} x} j k \rho c u_{1 a}=-\frac{\mathrm{d} p_{1 a}}{\mathrm{~d} x} ;
$$

$$
\left[\begin{array}{c}
\mathrm{d} p_{1} / \mathrm{d} x \\
\mathrm{~d} \rho c u_{1} / \mathrm{d} x \\
\mathrm{~d} p_{1 a} / \mathrm{d} x \\
\mathrm{~d} \rho c u_{1 a} / \mathrm{d} x
\end{array}\right]=\left[\begin{array}{cccc}
0 & -j k & 0 & 0 \\
-j \alpha_{1} / k & 0 & -j \alpha_{2} / k & 0 \\
0 & 0 & 0 & -j k \\
-j \alpha_{3} / k & 0 & -j \alpha_{4} / k & 0
\end{array}\right]\left[\begin{array}{c}
p_{1} \\
\rho c u_{1} \\
p_{1 a} \\
\rho c u_{1 a}
\end{array}\right]=[\mathrm{N}]\left[\begin{array}{c}
p_{1} \\
\rho c u_{1} \\
p_{1 a} \\
\rho c u_{1 a}
\end{array}\right]
$$

Taking Eq. (8) into Eq. (7), the transfer matrix of perforated mufflers is obtained as

$$
\left[\begin{array}{c}
p_{1} \\
\rho_{0} c_{0} u_{1}
\end{array}\right]=[\mathrm{T}]\left[\begin{array}{c}
p_{2} \\
\rho_{0} c_{0} u_{2}
\end{array}\right]=\left[\begin{array}{cc}
A & B \\
C & D
\end{array}\right]\left[\begin{array}{c}
p_{2} \\
\rho_{0} c_{0} u_{2}
\end{array}\right]
$$

where:

$$
\begin{aligned}
& A=R_{11}-\left(R_{13}+j R_{14} \tan \left(k l_{b}\right)\right)\left(R_{41}+j R_{31} \tan \left(k l_{a}\right)\right) / Z \\
& B=R_{12}-\left(R_{13}+j R_{14} \tan \left(k l_{b}\right)\right)\left(R_{42}+j R_{32} \tan \left(k l_{a}\right)\right) / Z \\
& C=R_{21}-\left(R_{23}+j R_{24} \tan \left(k l_{b}\right)\right)\left(R_{41}+j R_{31} \tan \left(k l_{a}\right)\right) / Z \\
& D=R_{22}-\left(R_{23}+j R_{24} \tan \left(k l_{b}\right)\right)\left(R_{42}+j R_{32} \tan \left(k l_{a}\right)\right) / Z \\
& Z=R_{43}+j R_{44} \tan \left(k l_{b}\right)+j \tan \left(k l_{a}\right)\left(R_{33}+j R_{34} \tan \left(k l_{b}\right)\right)
\end{aligned}
$$

\section{APPENDIX B. THE NUMERICAL EXPERI- MENTAL RESULTS OF THE TAGUCHI AR- RAY}

The numerical experimental results of the Taguchi array are presented in Table 6 (on the next page).

\section{REFERENCES}

1 Sullivan, J. W. and Crocker, M. J. Analysis of concentrictube resonators having unpartitioned cavities, The Journal of the Acoustical Society of America, 64, 207-215, (1978). http://dx.doi.org/10.1121/1.381963

2 Jayaraman, K. and Yam, K. Decoupling approach to modelling perforated tube muffler components, The Journal of the Acoustical Society of America, 69, 390-396, (1981). http://dx.doi.org/10.1121/1.385465

3 Munjal, M. L. Acoustics of Ducts and Mufflers. WileyInterscience Publication, New York, (1987).

4 Vijayasree, N. K. and Munjal, M. L. On an Integrated Transfer Matrix method for multiply connected mufflers, Journal of Sound and Vibration, 331 (8), 1926-1938, (2012). http://dx.doi.org/10.1016/j.jsv.2011.12.003

5 Barbieri, R., Barbieri, N., and Fonseca de Lima, K. Application of the Galerkin-FEM and the improved four-pole parameter method to predict acoustic performance of expansion chambers, Journal of Sound and Vibration, 276 (3), 1101-1107, (2004). http://dx.doi.org/10.1016/j.jsv.2003.11.063

${ }^{6}$ Kirby R. A comparison between analytic and numerical methods for modelling automotive dissipative silencers with mean flow, Journal of Sound and Vibration, 325 (3), 565-582, (2009). http://dx.doi.org/10.1016/j.jsv.2009.03.032
7 Wu, T. W., Zhang P., and Cheng, C. Y. R. Boundary element analysis of mufflers with an improved method for deriving the four-pole parameters, Journal of Sound and Vibration, 217 (4), 767-779, (1998). http://dx.doi.org/10.1006/jsvi.1998.1800

$8 \mathrm{Ji}$, Z. L., Selamet, A. Boundary element analysis of three-pass perforated duct mufflers, Noise Control Engineering Journal, 48 (5), 151-156, (2000). http://dx.doi.org/10.3397/1.2827962

9 Chang, Y. C. and Chiu, M. C. Shape optimization of one-chamber cross-flow mufflers by GA optimization, Journal of Mechanics, 24 (01), 13-29, (2008). http://dx.doi.org/10.1017/s1727719100001520

10 Chiu, M. C. and Chang, Y. C. Numerical studies on venting system with multi-chamber perforated mufflers by GA optimization, Applied Acoustics, 69 (11), 1017-1037, (2008). http://dx.doi.org/10.1016/j.apacoust.2007.07.002

11 Chang, Y. C. and Chiu, M. C. Optimization of multichamber mufflers with reverse-flow ducts by algorithm of simulated annealing, Archives of Acoustics, 35 (1), 13-33, (2010). http://dx.doi.org/10.2478/v10168-010-0002-8

12 Airaksinen, T. and Heikkola, E. Multi-objective muffler shape optimization with hybrid acoustics modelling. The Journal of the Acoustical Society of America, 130, 1359, (2011). http://dx.doi.org/10.1121/1.3621119

13 Chang, Y. C., Chiu, M. C., and Wu, L. W. Shape optimization of mufflers hybridized with multiple connected tubes using the boundary element method, neural networks, and genetic algorithm, Proceedings of the Institution of Mechanical Engineers, Part C: Journal of Mechanical Engineering Science, 224 (4), 901-913, (2010). http://dx.doi.org/10.1243/09544062jmes 1891

14 Chang, Y. C., Chiu, M. C., and Hsieh, C. C. Optimum Design of mufflers hybridized with one-connected curved tube using the boundary element method, neural networks, and the genetic algorithm, Journal of $\mathrm{Ma}$ rine Science and Technology, 20 (4), 376-383, (2012). http://dx.doi.org/10.6119/JMST-011-0303-1

15 Auregan, Y., Debray, A., and Starobinski, R. Low frequency sound propagation in a coaxial cylindrical duct: application to sudden area expansion and to dissipative silencers, Journal Sound and Vibration, 243 (3), 461-473, (2001). http://dx.doi.org/10.1006/jsvi.2000.3424

16 Lee. I., Acoustic characteristics of perforated dissipative and hybrid silencers. Ph.D. 
Table 6. Experimental results ( $L_{49}$ orthogonal array).

\begin{tabular}{|c|c|c|c|c|c|c|c|c|c|}
\hline No. & $\overline{d d(\mathrm{~m})}$ & $\overline{D D / d}$ & $\overline{l l(\mathrm{~m})}$ & $\overline{l_{c} / l}$ & $\bar{t} t(\mathrm{~m})$ & $\overline{d_{h}(\mathrm{~m})}$ & $\bar{\eta}$ & $\alpha$ & $\overline{t_{e}(\mathrm{~m})}$ \\
\hline 1 & 1 & 1 & 1 & 1 & 1 & 1 & 1 & 1.3 & 0.016 \\
\hline 2 & 1 & 2 & 5 & 3 & 4 & 5 & 2 & 0.73 & 0.02328 \\
\hline 3 & 1 & 3 & 2 & 5 & 7 & 2 & 3 & 1.08 & 0.02191 \\
\hline 4 & 1 & 4 & 6 & 7 & 3 & 6 & 4 & 0.78 & 0.018 \\
\hline 5 & 1 & 5 & 3 & 2 & 6 & 3 & 5 & 1.2 & 0.01733 \\
\hline 6 & 1 & 6 & 7 & 4 & 2 & 7 & 6 & 1.2 & 0.01765 \\
\hline 7 & 1 & 7 & 4 & 6 & 5 & 4 & 7 & 1.76 & 0.01789 \\
\hline 8 & 2 & 4 & 7 & 3 & 6 & 4 & 1 & 0.83 & 0.03482 \\
\hline 9 & 2 & 5 & 4 & 5 & 2 & 1 & 2 & 2.33 & 0.01961 \\
\hline 10 & 2 & 6 & 1 & 7 & 5 & 5 & 3 & 1.03 & 0.02495 \\
\hline 11 & 2 & 7 & 5 & 2 & 1 & 2 & 4 & 2.23 & 0.01594 \\
\hline 12 & 2 & 1 & 2 & 4 & 4 & 6 & 5 & 0.8 & 0.016 \\
\hline 13 & 2 & 2 & 6 & 6 & 7 & 3 & 6 & 1.26 & 0.0185 \\
\hline 14 & 2 & 3 & 3 & 1 & 3 & 7 & 7 & 0.86 & 0.01326 \\
\hline 15 & 3 & 7 & 6 & 5 & 4 & 7 & 1 & 0.86 & 0.03886 \\
\hline 16 & 3 & 1 & 3 & 7 & 7 & 4 & 2 & 0.8 & 0.02889 \\
\hline 17 & 3 & 2 & 7 & 2 & 3 & 1 & 3 & 2.2 & 0.01727 \\
\hline 18 & 3 & 3 & 4 & 4 & 6 & 5 & 4 & 1.03 & 0.02265 \\
\hline 19 & 3 & 4 & 1 & 6 & 2 & 2 & 5 & 2.3 & 0.0155 \\
\hline 20 & 3 & 5 & 5 & 1 & 5 & 6 & 6 & 1.13 & 0.01869 \\
\hline 21 & 3 & 6 & 2 & 3 & 1 & 3 & 7 & 2.3 & 0.01421 \\
\hline 22 & 4 & 3 & 5 & 7 & 2 & 3 & 1 & 1.32 & 0.02743 \\
\hline 23 & 4 & 4 & 2 & 2 & 5 & 7 & 2 & 0.7 & 0.02889 \\
\hline 24 & 4 & 5 & 6 & 4 & 1 & 4 & 3 & 1.53 & 0.02102 \\
\hline 25 & 4 & 6 & 3 & 6 & 4 & 1 & 4 & 3.4 & 0.02077 \\
\hline 26 & 4 & 7 & 7 & 1 & 7 & 5 & 5 & 1.3 & 0.02367 \\
\hline 27 & 4 & 1 & 4 & 3 & 3 & 2 & 6 & 2.3 & 0.01403 \\
\hline 28 & 4 & 2 & 1 & 5 & 6 & 6 & 7 & 1.1 & 0.01851 \\
\hline 29 & 5 & 6 & 4 & 2 & 7 & 6 & 1 & 0.7 & 0.04036 \\
\hline 30 & 5 & 7 & 1 & 4 & 3 & 3 & 2 & 1.56 & 0.02622 \\
\hline 31 & 5 & 1 & 5 & 6 & 6 & 7 & 3 & 0.82 & 0.02764 \\
\hline 32 & 5 & 2 & 2 & 1 & 2 & 4 & 4 & 1.12 & 0.01538 \\
\hline 33 & 5 & 3 & 6 & 3 & 5 & 1 & 5 & 3.6 & 0.02033 \\
\hline 34 & 5 & 4 & 3 & 5 & 1 & 5 & 6 & 1.78 & 0.01806 \\
\hline 35 & 5 & 5 & 7 & 7 & 4 & 2 & 7 & 4.2 & 0.02184 \\
\hline 36 & 6 & 2 & 3 & 4 & 5 & 2 & 1 & 1.27 & 0.03075 \\
\hline 37 & 6 & 3 & 7 & 6 & 1 & 6 & 2 & 1.15 & 0.02681 \\
\hline 38 & 6 & 4 & 4 & 1 & 4 & 3 & 3 & 1.4 & 0.02182 \\
\hline 39 & 6 & 5 & 1 & 3 & 7 & 7 & 4 & 0.95 & 0.02692 \\
\hline 40 & 6 & 6 & 5 & 5 & 3 & 4 & 5 & 2.3 & 0.02451 \\
\hline 41 & 6 & 7 & 2 & 7 & 6 & 1 & 6 & 5 & 0.02294 \\
\hline 42 & 6 & 1 & 6 & 2 & 2 & 5 & 7 & 1.52 & 0.01516 \\
\hline 43 & 7 & 5 & 2 & 6 & 3 & 5 & 1 & 1.11 & 0.03521 \\
\hline 44 & 7 & 6 & 6 & 1 & 6 & 2 & 2 & 1.8 & 0.03056 \\
\hline 45 & 7 & 7 & 3 & 3 & 2 & 6 & 3 & 1.36 & 0.02709 \\
\hline 46 & 7 & 1 & 7 & 5 & 5 & 3 & 4 & 1.9 & 0.02385 \\
\hline 47 & 7 & 2 & 4 & 7 & 1 & 7 & 5 & 1.5 & 0.02267 \\
\hline 48 & 7 & 3 & 1 & 2 & 4 & 4 & 6 & 1.58 & 0.01751 \\
\hline 49 & 7 & 4 & 5 & 4 & 7 & 1 & 7 & 5 & 0.02158 \\
\hline
\end{tabular}

Thesis, The Ohio State University, (2005). http://rave.ohiolink.edu/etdc/view?acc_num=osu1117631229.

17 Crandall, I. B. Theory of Vibrating Systems and Sound. Princeton: D. Van Nostrand Company, (1926).

18 Mechel, F. P., Formulas of Acoustics. Springer, New York, (2002).

19 Elnady, T., and H. Boden, H. On the modelling of the acoustic impedance of perforates with flow,. 9th AIAA/CEAS Aeroacoustics Conference, (2003). http://dx.doi.org/10.2514/6.2003-3304

20 Taguchi, G. Introduction to Qquality Eengineering, Asia Productivity Organization, UNIPUB, White Plains, New York, (1886).

21 Cai, J. C., Qi, D. T., Lu, F. A., and Wen, X. F. Study of the tonal casing noise of a centrifugal fan at the blade pass- ing frequency. Part I. Aeroacoustics, Journal of Low Frequency Noise, Vibration and Active Control, 29 (4), 253 266, (2010). http://dx.doi.org/10.1260/0263-0923.29.4.253

22 Deb, K., Pratap, A., Agarwal, S., and Meyarivan, T. A. M. T. A fast and elitist multi-objective genetic algorithm: NSGA-II, IEEE Transactions on Evolutionary Computation, 6 (2), 182-197, (2002). http://dx.doi.org/10.1109/4235.996017

23 Tao, Z., and Seybert, A. F. A review of current techniques for measuring muffler transmission loss, SAE International, 01-1653, (2003). http://dx.doi.org/10.4271/2003-01-1653

24 Lee, I. J., Selamet, A., Kim, H., et al., Design of a multi-chamber silencer for turbocharger noise, SAE International Journal of Passenger Cars-Mechanical Systems, 2 (1), 1339-1344, (2009). http://dx.doi.org/10.4271/2009-012048 